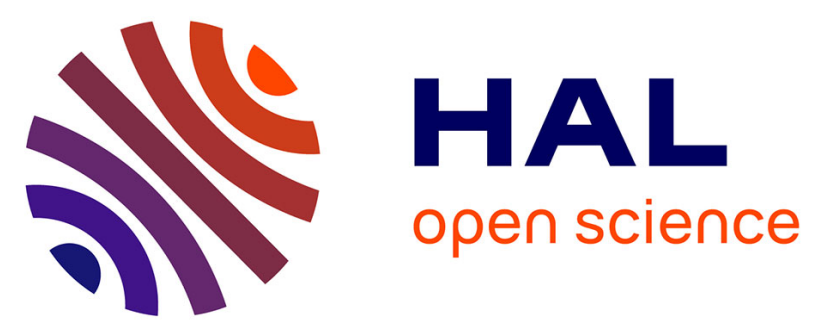

\title{
Uranyl interaction with the hydrated (0001) basal face of gibbsite: A combined theoretical and spectroscopic study
}

Edouard Veilly, Jérôme Roques, Marie-Camille Jodin-Caumon, Bernard Humbert, Romuald Drot, Eric Simoni

\section{To cite this version:}

Edouard Veilly, Jérôme Roques, Marie-Camille Jodin-Caumon, Bernard Humbert, Romuald Drot, et al.. Uranyl interaction with the hydrated (0001) basal face of gibbsite: A combined theoretical and spectroscopic study. Journal of Chemical Physics, 2008, 129, pp.244704. 10.1063/1.3042142 . hal-01342004

\section{HAL Id: hal-01342004 \\ https://hal.science/hal-01342004}

Submitted on 5 Jul 2016

HAL is a multi-disciplinary open access archive for the deposit and dissemination of scientific research documents, whether they are published or not. The documents may come from teaching and research institutions in France or abroad, or from public or private research centers.
L'archive ouverte pluridisciplinaire $\mathbf{H A L}$, est destinée au dépôt et à la diffusion de documents scientifiques de niveau recherche, publiés ou non, émanant des établissements d'enseignement et de recherche français ou étrangers, des laboratoires publics ou privés. 


\title{
Uranyl interaction with the hydrated $(001)$ basal face of gibbsite: A combined theoretical and spectroscopic study
}

\author{
Edouard Veilly, ${ }_{1}^{1}$ Jérôme Roques, ${ }^{1, a)}$ Marie-Camille Jodin-Caumon, ${ }^{2}$ Bernard Humbert, ${ }^{2}$ \\ Romuald Drot, ${ }^{1}$ and Eric Simoni ${ }^{1}$ \\ ${ }_{1}^{1}$ Institut de Physique Nucléaire d'Orsay, Université Paris-Sud 11, CNRS UMR 8608, 15 Rue Georges \\ Clémenceau, Bâtiment 100, 91406 Orsay Cedex, France \\ ${ }^{2}$ Laboratoire de Chimie Physique et Microbiologie pour l'Environnement, CNRS UMR 7564, \\ 405 Rue de Vandoeuvre, 54600 Villers-lès-Nancy, France
}

(Received 2 September 2008; accepted 10 November 2008; published online 24 December 2008)

\begin{abstract}
The sorption of uranyl cations and water molecules on the basal (001) face of gibbsite was studied by combining vibrational and fluorescence spectroscopies together with density functional theory (DFT) computations. Both the calculated and experimental values of $\mathrm{O}-\mathrm{H}$ bond lengths for the gibbsite bulk are in good agreement. In the second part, water sorption with this surface was studied to take into account the influence of hydration with respect to the uranyl adsorption. The computed water configurations agreed with previously published molecular dynamics studies. The uranyl adsorption in acidic media was followed by time-resolved laser-induced fluorescence spectroscopy and Raman spectrometry measurements. The existence of only one kind of adsorption site for the uranyl cation was then indicated in good agreement with the DFT calculations. The computation of the uranyl adsorption has been performed by means of a bidentate interaction with two surface oxygen atoms. The optimized structures displayed strong hydrogen bonds between the surface and the -yl oxygen of uranyl. The uranium-surface bond strength depends on the protonation state of the surface oxygen atoms. The calculated $\mathrm{U}-\mathrm{O}_{\text {surface }}$ bond lengths range between 2.1-2.2 and 2.6-2.7 $\AA$ for the nonprotonated and protonated surface O atoms, respectively. () 2008 American Institute of Physics. [DOI: 10.1063/1.3042142]
\end{abstract}

\section{INTRODUCTION}

Sorption mechanisms on minerals are involved in retarding migration of uranium into soils and sediments. ${ }^{1}$ In aquifer media, the different hydrolyzed species of uranium involve the formal oxidation state (VI). ${ }^{2}$ Sorption on gibbsite $\mathrm{Al}(\mathrm{OH})_{3}$ is of interest mainly because of the abundance of this aluminum hydroxyl mineral in soils. Two time-resolved laser-induced fluorescence spectroscopy (TRLFS) studies ${ }^{3,4}$ have shown that two kinds of surface complexes, a type of $\mathrm{Al}-\mathrm{UO}_{2}{ }^{2+}$ complex and a polynuclear one at high $p \mathrm{H}$ values, may be considered to account for experimental results. Nevertheless, the nature and the composition of the adsorbed complexes are not fully understood. For example, it is difficult to assign any component of the extended x-ray adsorption fine structure (EXAFS) and TRLFS studies of Froideval et al..$^{5}$ because of the formation of an amorphous aluminum hydroxide during adsorption experiments. The study of Hongxia $e t a l .{ }^{6}$ has shown that the insensitive effect of the ionic strength on uranyl sorption on $\mathrm{Al}_{2} \mathrm{O}_{3}$ and $\mathrm{Al}(\mathrm{OH})_{3}$ may be interpreted as the formation of strong chemical bonds between the sorbed species and the surfaces of $\mathrm{Al}_{2} \mathrm{O}_{3}$ and $\mathrm{Al}(\mathrm{OH})_{3}$. Furthermore, the comparison of sorption on gibbsite of the uranyl cations allowed these authors to assume that the sorption processes of $\mathrm{UO}_{2}{ }^{2+}$ are more complex than those of $\mathrm{Cu}(\mathrm{II}), \mathrm{Cd}(\mathrm{II})$, and $\mathrm{Pb}(\mathrm{II}){ }^{6}$

\footnotetext{
${ }^{a)}$ Tel.: $+33(0) 169156869$. FAX: $+33(0) 169157150$. Electronic mail: roques@ipno.in2p3.fr.
}

Understanding sorption mechanisms requires the exact knowledge of surface structures and properties at the atomic scale. However, it is difficult to record molecular features from surfaces without a strong overlap with signals coming from the bulk. Only the optical nonlinear and photoelectron spectroscopies are able to collect direct information from surfaces. Unfortunately, those kinds of methods are not easily usable for powders or require an analysis under ultravacuum. Such limitations complicate the application of these techniques for in situ analysis of solid-solution interfaces for colloidal particles. Vibrational spectroscopy near-field experiments, which record vibration signals of surface groups of powder samples, are not yet able to detect the specific signal of $\mathrm{OH}$ groups. ${ }^{7}$ This lack of experimental data at the molecular level has led the scientific community to extrapolate the speciation of the surface groups from the bulk structure, even if relaxation effects are known to modify atomic organization at mineral surfaces (e.g., gibbsite $^{8}$ ).

Quantum molecular modeling applied to gibbsite has led to only three papers, two dealing with the bulk properties of gibbsite $^{9,10}$ and one modeling the IR and Raman spectra of gibbsite. ${ }^{11}$ Gale et al. ${ }^{9}$ used both periodic density functional theory (DFT) and a localized basis set approach in order to determine crystallographic parameters and some physical properties as the full elastic constant tensor and the bulk modulus, together with the frequencies of hydroxyl group stretching modes. Digne et al. ${ }^{10}$ studied all the naturally occurring hydroxide aluminum phases using the generalized gradient approximation (GGA) to describe the exchange- 
correlation potential. Their results were in agreement with experimental crystallographic data ${ }^{12}$ and allowed one to describe the hydrogen bonds. On this basis, their thermodynamical study demonstrated the highest stability of gibbsite compared to the other aluminum (hydr)oxide compounds.

The aim of this paper is to investigate the interfacial processes between gibbsite and uranyl cations in weakly acidic aqueous solutions. Our experiments have been carried out for samples prepared at $p \mathrm{H} 3$. This value was chosen since at this $p \mathrm{H}$, only the free aqueous $\mathrm{UO}_{2}{ }^{2+}$ ion is present in solution and thus expected to be sorbed, while the dissolution of gibbsite is still limited. ${ }^{13}$ In this context, the identification of the number of surface species will be simplified. Besides, the works of Hiemstra and Riemsdijk ${ }^{14}$ and Hiemstra et al. ${ }^{15}$ confirmed by Jodin et al., ${ }^{16}$ showed that the (001) faces only bear uncharged $\mathrm{OH}$ groups bonded to two $\mathrm{Al}$ atoms $\left[\mathrm{Al}_{2}(\mathrm{OH})\right]$ for $p \mathrm{H}$ values between 4 and 10 , whereas edge faces exhibit both doubly and singly coordinated hydroxyl groups $(\mathrm{Al}-\mathrm{OH})$. The latter are positively charged for $p \mathrm{H}$ values smaller than 8 . Thus in our acidic conditions, the sorption of uranyl on gibbsite will be only considered on the (001) basal faces. First, the bulk properties and the basal (001) plane structure and properties of gibbsite are investigated. Then, the interactions of water molecules and uranyl cations under a reduced water pressure with the basal plane are computed as a function of gibbsite surface properties on the basis of spectroscopic experimental data.

\section{MATERIALS AND METHODS}

Computational details. Periodic DFT calculations with the Vienna $a b$ initio simulation package (VASP) code were used. ${ }^{17}$ The Kohn-Sham equations were solved within the GGA, as proposed by Perdew and Wang, ${ }^{18}$ to evaluate the exchange-correlation energy. Generated projector augmented wave pseudopotentials were used. ${ }^{19}$ The pseudopotentials for $\mathrm{Al}$ atoms have as valence electrons $3 s^{2} 3 p^{1}$; those for oxygen atoms have $2 s^{2} 2 p^{4}$. Integrations in the Brillouin zone were performed using different $k$ point sets generated with the Monkhorst-Pack grid, centered at the $\Gamma$-point, ${ }^{20}$ and a Methfessel-Paxton smearing of $0.3 \mathrm{eV}$ for calculations involving the presence of the uranyl ion. ${ }^{21}$ Spin polarized calculations were carried out when the uranyl ion interacts with the surface. For a charged unit cell, a neutralizing background charge was assumed by VASP. The geometry optimization was performed using the conjugate gradient optimization scheme with a convergence criterion of $0.001 \mathrm{eV} / \AA$ on forces.

Gibbsite preparation. Gibbsite synthesis is described in detail by Jodin et al. $^{22}$ Briefly, gibbsite particles were obtained by aging a supersaturated solution of sodium aluminate (Bayer liquor) prepared by oxidation of metallic aluminum in a concentrated sodium hydroxide solution. The solid particles were separated from the solution by centrifugation, then washed several times with a diluted nitric acid solution at $p \mathrm{H}=4.0$, and, finally, washed once with Milli-Q water. Next, the sample was dialyzed against Milli-Q water until the conductivity stabilized at a value close to that of Milli-Q water $(0.5 \mathrm{~S} / \mathrm{cm})$. The specific surface area measured by krypton adsorption at $77 \mathrm{~K}$ was equal to $4 \mathrm{~m}^{2} \mathrm{~g}^{-1}$, distributed as $1.5 \mathrm{~m}^{2} \mathrm{~g}^{-1}$ of lateral specific surface area and $2.5 \mathrm{~m}^{2} \mathrm{~g}^{-1}$ of basal specific surface area. This distribution is coherent with our previous measurements ${ }^{23,24}$ and statistical analysis of atomic force microscopic images. ${ }^{22}$

Uranyl adsorption. A uranyl stock solution (about 2.5 $\left.\times 10^{-2} M\right)$, named U6S in the following text, was obtained by dissolving a weighted amount of $\mathrm{UO}_{2}\left(\mathrm{NO}_{3}\right)_{2} \cdot 6 \mathrm{H}_{2} \mathrm{O}$ (Merck) solid in a previously acidified $(p \mathrm{H}=1) \mathrm{NaClO}_{4} 1 M$ solution in order to avoid cation hydrolysis. All other chemicals were of analytical grade, and Milli-Q water was used in all experiments. Sorption experiments were carried out at room temperature in polypropylene tubes at low $p \mathrm{H}$ values $(p \mathrm{H}=3)$ in order to ensure that only free aqueous uranyl ions are present in the solution. ${ }^{25}$ Therefore, only this species is expected to be sorbed on the substrate. Two different ionic strength values $(\mu=0.1 M$ or $1 M)$ were considered, and the initial U(VI) concentration was varied from $10^{-4} M$ to $10^{-3} M$. For each experiment, $200 \mathrm{mg}$ of solid were contacted, for $24 \mathrm{~h}$ under continuous stirring, with $10 \mathrm{ml}$ of the uranium containing solution. This solution was obtained as follows: $9.6 \mathrm{ml}$ of a background solution $\left(\mathrm{NaClO}_{4}, 1 M\right)$ adjusted at the desired $p \mathrm{H}$ value with a negligible volume of concentrated $\mathrm{HClO}_{4}$ solution and $0.4 \mathrm{ml}$ of $\mathrm{U} 6 \mathrm{~S}\left(\mu=1 M\right.$; $\left.[\mathrm{U}]_{\text {ini }}=10^{-3} M\right) ; 9.96 \mathrm{ml}$ $\left(\mathrm{NaClO}_{4}, 1 M, p \mathrm{H}=3\right)$ and $0.04 \mathrm{ml}$ of $\mathrm{U} 6 \mathrm{~S}\left(\mu=1 M\right.$; $[\mathrm{U}]_{\mathrm{ini}}$ $\left.=10^{-4} M\right) ; 9.6 \mathrm{ml}\left(\mathrm{NaClO}_{4}, 0.1 M, p \mathrm{H}=3\right)$ and $0.4 \mathrm{ml}$ of $\mathrm{U} 6 \mathrm{~S}$ $\left(\mu=0.1 M ;[\mathrm{U}]_{\mathrm{ini}}=10^{-4} M\right)$; and $9.96 \mathrm{ml}\left(\mathrm{NaClO}_{4}, 0.1 M, p \mathrm{H}\right.$ $=3)$ and $0.04 \mathrm{ml}$ of U6S $\left(\mu=0.1 M\right.$; $\left.[\mathrm{U}]_{\text {ini }}=10^{-4} M\right)$. Considering the low $p \mathrm{H}$ value $(p \mathrm{H}=3)$ of the solutions, one can exclude the presence of dissolved carbon dioxide. Thus, no uranium-carbonate species is present in our experiments.

Fluorescence spectroscopy. TRLFS experiments were carried out at room temperature on in situ samples using a tunable OPO Panther Continuum laser as the excitation source at $430 \mathrm{~nm}$ (with pulse length around $7 \mathrm{~ns}$ ) in order to obtain the best signal-to-noise ratio. Spectra were collected using a Spectra-Pro-300 monochromator (Acton Research Corporation) coupled with a charge coupled device (CCD) camera (Princeton Instruments). The emission spectra were recorded in the range of 450-600 $\mathrm{nm}$ using the software WINSPEC (Princeton Instruments). The time-dependent emission decays were fitted to (multi)exponential laws. The accuracy of the determined lifetimes is about $10 \%$ (variation in the decay time value for several samples prepared in the same conditions).

Infrared spectroscopy. Infrared spectra were obtained with a Perkin Elmer System 2000 Fourier transform infrared spectrometer. Powder spectra of gibbsite samples from pure powder were recorded in either attenuated total reflection or diffuse reflectance infrared Fourier transform (DRIFT) modes. The detector used was a broad band deuterated triglyceride sulfate (DTGS). The infrared beam was shaped by using different pinholes (beam stop and Jacquinot stop) to improve signal properties (beam divergence, signal/noise ratio, spectral resolution, subtraction of water vapor rovibrational spectra between reference and sample signals, and reproducibility). The acquisition time was $1 \mathrm{~min} / \mathrm{spectrum}$, and the spectral resolution was $4 \mathrm{~cm}^{-1}$. The infrared experimental wavenumber accuracy was better than $0.01 \mathrm{~cm}^{-1}$. 


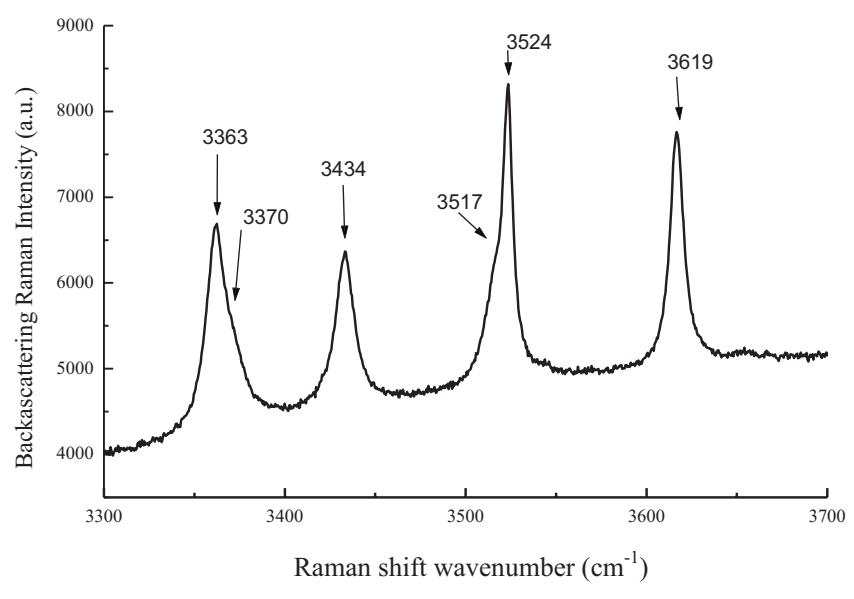

FIG. 1. Raw Raman spectrum of gibbsite powder.

Raman spectroscopy. The Raman spectra of gibbsite powder were recorded with a triple subtractive monochromator T64000 Jobin Yvon spectrometer equipped with a confocal microscope. The detector was a CCD cooled by liquid nitrogen. The Raman spectra were excited by a laser beam at $541.53 \mathrm{~nm}$ emitted by an argon laser (Stabilite 2017, Spectra Physics) focused on samples with a diameter of about $1.5 \mu \mathrm{m}$ and a power of about $20 \mathrm{~mW}$. The Raman backscattering was collected through the microscope lens $(\times 50)$ and dispersed by an 1800 groves $/ \mathrm{mm}$ grating to obtain a spectral resolution of $2.7 \mathrm{~cm}^{-1}$. Wavenumber accuracy in vacuum was better than $0.8 \mathrm{~cm}^{-1}$.

\section{RESULTS AND DISCUSSION}

\section{A. Bulk structure}

Gibbsite polymorph has a sheet structure, crystallizing usually in pseudohexagonal platelets with monoclinic symmetry. All of the polymorphs of $\mathrm{Al}(\mathrm{OH})_{3}$ are composed of layers of aluminum atoms located in two-thirds of the octahedral sites with hydroxyl groups on either side, half of these groups bonding the layers together. The stacking sequence of layers only differentiates gibbsite from the other polymorphs. The stacking structures of gibbsite and bayerite were thoroughly described by Giese Jur. ${ }^{26}$ Saalfeld and Weede ${ }^{12}$ refined the crystal structure in the centrosymmetric space group $P 2_{1} / n\left(C_{2 h}{ }^{5}\right)$ from x-ray diffraction (XRD) patterns. Their results and assignments have been recently confirmed by Mercury et al. ${ }^{27}$ The low electronic density of hydrogen limits significantly the XRD technique in describing accurately hydroxyl groups in terms of $\mathrm{H}$ positions and thus $\mathrm{O}-\mathrm{H}$ distances. This situation is usually tackled by using neutron diffraction (ND) and/or vibrational spectroscopy. ND data for gibbsite were reported by Mercury et al. ${ }^{27}$ but, unfortunately, the authors were unable to locate the $\mathrm{H}$ atoms during the Rietveld analysis.

The Raman spectrum of the studied gibbsite powder in the 3300-3700 wavenumber range is presented in Fig. 1. This spectrum shows that the powder used in this work is a pure phase of the gibbsite structure. Polarized Raman measurements obtained on a single crystal, in the way previously described by Wang and Johnson, ${ }^{28}$ were very similar to those

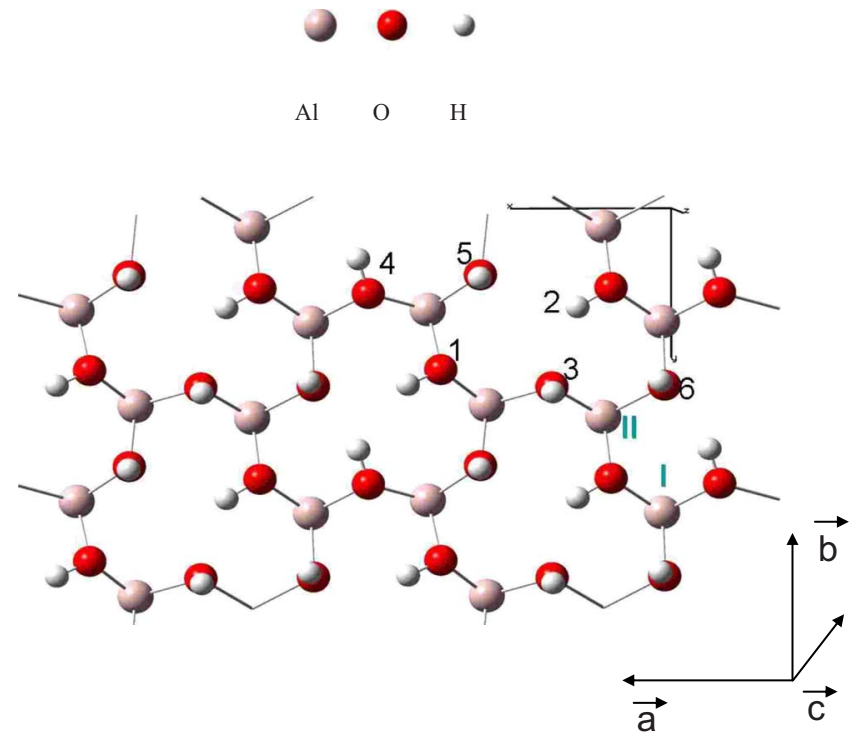

FIG. 2. (Color online) Hydrogen (1-6) and aluminum (I-II) notations. (001) view of gibbsite.

obtained by these authors. The six gibbsite components were located at 3619,3524 , and $3517 \mathrm{~cm}^{-1}$ (related to $\mathrm{OH}$ inplane numbers 1, 2, and 4, respectively; see Fig. 2) and at 3434,3370 , and $3363 \mathrm{~cm}^{-1}$ (related to $\mathrm{OH}$ out-of-plane numbers 6, 3, and 5, respectively; see Fig. 2). This qualitative spectral assignment was obtained from the measurements recorded in the different polarization configurations. ${ }^{28,29}$

It is possible to measure $\mathrm{OH}$ bond lengths by infrared spectroscopy by recording uncoupled vibration of hydroxyl groups isolated in the gibbsite structure. ${ }^{30}$ This could be done following the infrared spectra of either OD groups diluted in a gibbsite $\mathrm{OH}$ structure or $\mathrm{OH}$ groups diluted in a gibbsite OD structure. Indeed, at low dilution, the chemical environment of each kind of hydroxyl group can be determined without any vibrational coupling between vibrating groups. Moreover, the consequences of TO-LO effects and particle shapes on the infrared absorptions are also avoided. ${ }^{11,23}$ In particular the absorption at $3460 \mathrm{~cm}^{-1}$, which was shown to be related to those effects, is not of interest to describe the bulk $\mathrm{O}-\mathrm{H}$ bonds. Therefore, we tried to deuterate a gibbsite sample in order to dilute $\mathrm{H}$ into $\mathrm{D}$, carrying out a synthesis of gibbsite in a $\mathrm{D}_{2} \mathrm{O}$ medium or putting gibbsite in $\mathrm{D}_{2} \mathrm{O}$. In both cases, the $\mathrm{H}$ dilution was not sufficient to uncouple all $\mathrm{O}-\mathrm{H}$ vibrators. However, it was possible to record the infrared spectra of uncoupled $\mathrm{O}-\mathrm{D}$ stretching vibrations diluted in a gibbsite $\mathrm{OH}$ structure using the DRIFT technique. The DRIFT method usually enhances a small signal, such as harmonic components, or a surface signal. Here it was used to record the $\mathrm{O}-\mathrm{D}$ stretching vibrations, deuterium being present at its natural atomic abundance, i.e., $0.015 \%$. The DRIFT spectra of gibbsite in the O-D stretching region show five peaks at 2667, 2603, 2548, 2519, and $2506 \mathrm{~cm}^{-1}$ (Fig. $3)$. From these wavenumbers and the wavenumber of $\mathrm{OH}$, the harmonic wavenumbers were calculated ${ }^{29}$ (Table I). From these spectral data, the lengths and the perturbation by the $\mathrm{H}$ bond of bulk $\mathrm{O}-\mathrm{H}$ groups (e.g., see Refs. 31 and 32) were estimated according to Herzberg: ${ }^{33}$ the harmonic wave- 


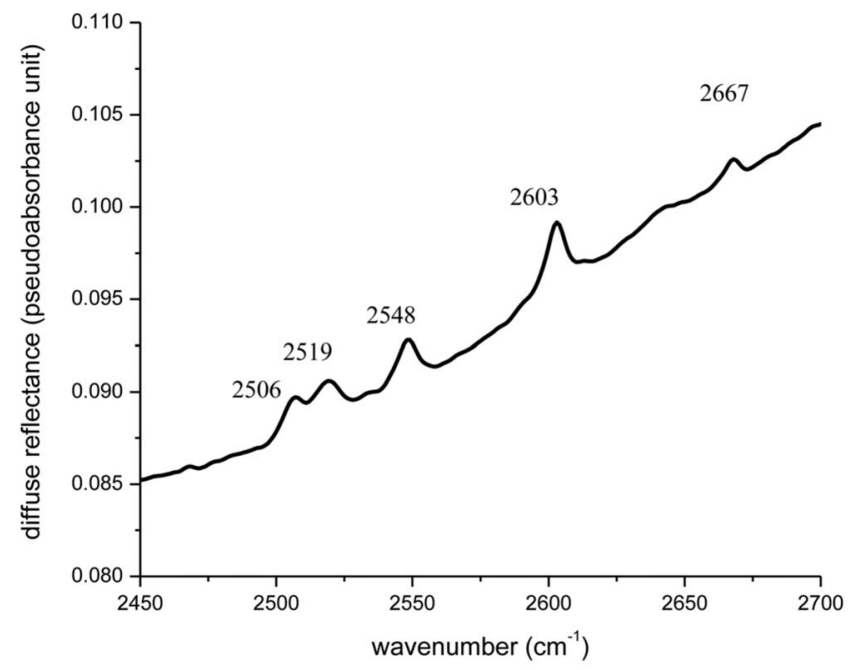

FIG. 3. DRIFT spectrum of a gibbsite sample in the O-D stretching region (D in natural abundance, i.e., $0.015 \%$ of $\mathrm{H}$ atoms).

number of each bulk stretching mode is linked to the nature and to the length of the corresponding bond via a linear relation between the harmonic wavenumber $\omega$ and the $\mathrm{O}-\mathrm{H}$ bond length $r_{e}$ depending on the nature of the $\mathrm{OH}$ group,

$$
\Delta \omega / \Delta r_{e}=-135 \mathrm{~cm}^{-1} / 0.01 \AA .
$$

This kind of empirical law was confirmed by a large number of studies on various systems, such as carboxylic acids, water in solvents, and mineral acids (e.g., see Refs. 33 and 34). The application of this law to both in-plane and out-of-plane $\mathrm{OH}$ groups in gibbsite structure yields $\mathrm{OH}$ bond lengths of 0.955 and $0.967 \AA(\Delta=0.012 \AA)$, respectively. As a comparison, the rule of Lutz and Jung, ${ }^{31}$ described for water molecules and hydroxide ions in solid hydrate, yields a similar range of bond lengths $(0.944-0.964 \AA, \Delta=0.020 \AA)$. The shortest bonds correspond to in-plane $\mathrm{O}-\mathrm{H}$ groups $(\mathrm{OH}$ numbers 1, 2, and 4) involved in the weakest $\mathrm{H}$ bonds. These values obtained from vibrational spectra are higher than the ones previously determined by XRD. Considering the H-bond network in this structure, $0.012 \AA$ was reasonable, while the crystallographic data provided an overestimated value of $0.13 \AA$. . $^{12,35}$

Those experimental results have to be compared now with an $a b$ initio study. At first, to estimate the cell parameters and the chemical bond distances, bulk calculations were carried out. To evaluate the crystallographic parameters, relaxation was performed in two steps: first, atomic positions

TABLE I. Experimental wavenumbers of OD stretching modes and deduced harmonic wavenumbers used in this paper to estimate the $\mathrm{OH}(\mathrm{D})$ distances since the values deduced from the XRD measurements are not adequate.

\begin{tabular}{ccc}
\hline \hline OH No. & $\begin{array}{c}\sigma_{\mathrm{OD}} \\
\left(\mathrm{cm}^{-1}\right)\end{array}$ & $\begin{array}{c}\omega_{\mathrm{OH}} \\
\left(\mathrm{cm}^{-1}\right)\end{array}$ \\
\hline 1 & 2668 & 3792 \\
$2 / 4$ & 2604 & 3739 \\
5 & 2548 & 3681 \\
6 & 2519 & 3658 \\
3 & 2507 & 3642 \\
\hline
\end{tabular}

TABLE II. Calculated and experimental gibbsite bulk parameters.

\begin{tabular}{lccc}
\hline \hline & Experimental $^{\mathrm{a}}$ & Calculated $^{\mathrm{b}}$ & This work \\
\hline$a(\AA)$ & 8.684 & 8.765 & 8.736 \\
$b(\AA)$ & 5.078 & 5.083 & 5.099 \\
$c(\AA)$ & 9.736 & 9.594 & 9.628 \\
$\beta(\mathrm{deg})$ & 94.54 & 92.63 & 92.83 \\
$V\left(\AA^{3}\right)$ & 428.0 & 427.0 & 428.4 \\
\hline \hline
\end{tabular}

${ }^{\text {a Saalfeld and Weede (Ref. 12) }}$

${ }^{\mathrm{b}}$ DFT calculations (Ref. 10).

are allowed to relax with a constant volume, and second, they are allowed to relax with an unconstrained volume. Starting from the experimental parameters of Saalfeld and Weede, ${ }^{12}$ the cell energy convergence with respect to the cutoff energy and the $k$ point sampling are first checked. Using an optimized $k$ point sampling of $(2 \times 4 \times 2)$ and a cutoff energy of $450 \mathrm{eV}$, good cell parameters are obtained, in comparison with experimental and previous calculated DFT results (see Table II). The $c$ parameter is slightly underestimated due to the GGA formalism used in this study. These optimized parameters will be used in this study for constant volume relaxations.

Saalfeld and Weede ${ }^{12}$ displayed values of 2.781, 2.829, and $2.888 \AA$ for $\mathrm{O}-\mathrm{H} \cdots \mathrm{H}$ interlayer bonds. Calculations give the following bond lengths: 2.706, 2.749, and $2.807 \AA$. A difference of about $0.1 \AA$ is found whatever the bond is. Calculations for out-of-plane and in-plane $\mathrm{O}-\mathrm{H}$ bond lengths for the bulk geometry generated average values (see Table SI-1 in Supporting Information for details ${ }^{36}$ ) of 0.991 and $0.981 \AA(\Delta d=0.010 \AA)$ in good agreement with the previously obtained experimental values determined from infrared absorptions ( $\Delta d=0.012 \AA)$. Our experimental and calculated results also agreed with those calculated by Balan et al. ${ }^{11}$ and Gale et al., 9 , who found $\mathrm{OH}$ bond lengths of 0.979-0.994 $\AA$ $(\Delta d=0.015 \AA) \quad$ and $\quad 0.974-0.988 \AA \quad(\Delta d=0.014 \AA)$, respectively.

\section{B. Molecular structure of the (001) face}

Since anion adsorption has been shown to be specific to the lateral faces, ${ }^{14,37}$ uranyl adsorption may be assumed to preferentially occur on the basal (001) face. The absence of cation adsorption on edges is coherent with the fact that in the $p \mathrm{H}$ range of $4-10$, the basal faces are uncharged while the lateral ones are positively charged. ${ }^{14,29}$ The infrared spectra of uranyl sorbed on the gibbsite sample confirmed this assumption: no change in the $\mathrm{OH}$ infrared absorption was observed, whereas changes were reported with sulfate ${ }^{29}$ or carboxylate anions; ${ }^{37}$ in particular the broad band at around $3460 \mathrm{~cm}^{-1}$, sensitive to anion adsorption, remained unchanged when uranyl was adsorbed.

Calculations were based on a (001) face with $\mathrm{OH}$ groups bicoordinated to aluminum atoms without any deprotonation effects, in agreement with our experiments at $p \mathrm{H} \mathrm{3}$. In order to model adsorption reaction on the (001) surface, it was necessary to evaluate the number of $\mathrm{Al}(\mathrm{OH})_{3}$ layers required to reproduce surface relaxation. The surface was built starting from the mean of the calculated bulk atomic positions 


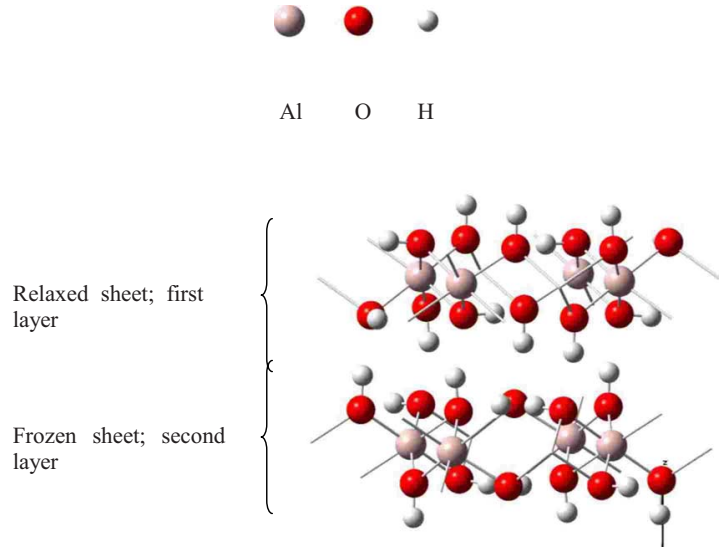

FIG. 4. (Color online) The two-layer gibbsite model used throughout the study.

using a $(2 \times 4 \times 1) k$ point sampling in accordance with the $(2 \times 4 \times 2) k$ point set used for the bulk calculations and a $450 \mathrm{eV}$ cutoff kinetic energy. Since VASP employs a threedimensional periodic boundary condition, a minimum of $10 \AA$ interslab distances were kept to ensure that the intermolecular interaction is sufficiently small.

In the first step, surface energy was calculated with a cell containing one to three layers (stacked up in the $c$ crystallographic direction), where all atoms were allowed to fully relax. Surface energy can be defined as

$$
E_{\text {surface }}=\frac{E_{\text {slab }}-E_{\mathrm{Al}(\mathrm{OH})_{3} \text { bulk }} \times N_{\mathrm{Al}(\mathrm{OH})_{3} \text { slab }}}{2 \times S},
$$

with $E_{\text {slab }}$ being the cell energy, $E_{\mathrm{Al}(\mathrm{OH})_{3} \text { bulk }}$ being the energy of a bulk unit cell, $N$ being the number of $\mathrm{Al}(\mathrm{OH})_{3}$ motifs in the slab, and $S$ being the geometric surface $a \times b$ $=44.54 \AA^{2}$. This expression is divided by two because of the symmetry of the cell. The calculated surface energies were $0.286,0.279$, and $0.276 \mathrm{eV} / \mathrm{m}^{2}$, from the one-layer to the three-layer model, respectively. The magnitude of these variations was low enough to assume that interactions between layers were weak. Second, we considered a partial relaxation of the surface. The Al-O bond lengths of the active (001) plane were calculated for three different surface models (see Table SI-2 in the Supporting Information ${ }^{36}$ ). Whatever the used model is, the bond lengths for both Al I and Al II atoms (Al numbering in Fig. 2) were similar. Therefore, the two-layer model, with one layer frozen at the bulk geometry, was an accurate model of the real (001) gibbsite surface (see Fig. 4).

In this two-layer model, the bond lengths of $\mathrm{OH}$ groups nearly perpendicular to the layers are $0.987(6), 0.985(5)$, and 0.983(3) $\AA$ ( $\mathrm{H}$ numbering from Fig. 2). These distances are slightly shorter than the equivalent ones computed in the bulk structure: $0.994(6), 0.992(5)$, and $0.988(3) \AA$. This is in good agreement with the fact that the latter were involved in interlayer hydrogen bonds. All the in-plane and out-of-plane hydrogen-bond characteristics are given in Table SI-1 of the Supporting Information. ${ }^{36}$

\section{C. $\mathrm{H}_{2} \mathrm{O}$ sorption on gibbsite}

Few theoretical studies were devoted to the reactivity of the (001) gibbsite plane with water, all of them using classical molecular dynamics. ${ }^{38,39}$ Simulations to study watersurface interactions considered six different mineral surfaces, ${ }^{39}$ with the models differing in surface coverage from zero to at least six monolayers. At the liquid watergibbsite surface interface, the $\mathrm{OH}$ groups, tilted toward vacant surface octahedral sites, were shown to become strongly preferred for the adsorption of $\mathrm{H}_{2} \mathrm{O}$ molecules, which accepted $\mathrm{H}$ bonds from the surface $\mathrm{OH}$ groups. The surface $\mathrm{OH}$ groups that were oriented almost parallel to the surface constitute the second kind of adsorption site that was H-bond acceptor from water molecules. Moreover, they showed that both donating and accepting $\mathrm{H}$ bonds of the $\mathrm{H}_{2} \mathrm{O}$ molecule create a hydrogen-bonding network across the interfacial region, as it was previously shown for kaolinite. ${ }^{40,41}$

As $\mathrm{H}_{2} \mathrm{O}$ adsorption takes place, thanks to a hydrogenbonding network, we chose to consider interfacial interactions with a maximum of three hydrogen bonds per water molecule. One surface hydroxyl site could create one or two hydrogen bonds toward the oxygen atom of the water molecule; in the same way one or two hydrogen atoms from the water molecule could participate in the interaction, binding with surface oxygen atoms [Figs. 5(a) and 5(b)].

On the basis of these adsorption configurations, four types of sites were defined. The presence of one or two outof-plane hydrogen atoms and the possible presence of an aluminum atom just under the site (because of the $2 / 3$ occupancy of the octahedral sites with aluminum atoms) differentiated the adsorption structures [Fig. 5(c)]. First, water adsorption energies at low coverage were determinated for interactions between water molecules with two out-of-plane hydroxyl groups [circles in Fig. 5(c)]. Five possibilities for this kind of interaction were found on the whole surface: two of them involve the presence of a sublayer aluminum atom, and three others without the latter. DFT calculations showed that adsorption energies were similar whatever the surface site is, ranging from 0.58 to $0.64 \mathrm{eV}$. Consequently, sublayer aluminum atoms do not exert any significant influence on the water adsorption energies. These results probably arise from the constrained octahedral configuration. One of the most stable structure (with $E_{\text {ads }}=0.64 \mathrm{eV}$ ) is structurally equivalent to the water interaction with the octahedral side of the kaolinite layer. $^{42}$

Second, water adsorption energies were calculated for sites exhibiting only one out-of-plane hydrogen atom [circles in Fig. 5(c)]. Adsorption energies for the six different configurations were found between 0.29 and $0.54 \mathrm{eV}$. Higher energies were observed for two sites with a sublayer $\mathrm{Al}$ atom (0.53 and $0.54 \mathrm{eV})$. Calculated adsorption energies for the four other sites are of $0.29,0.45,0.51$, and $0.54 \mathrm{eV}$. Consequently, considering these lower interaction energies with surface, these sites show somewhat longer hydrogen bond lengths in comparison with the sites with two out-of-plane hydrogen atoms. To conclude this part of this work, the presence of two out-of-plane hydrogen atoms per site led to strong adsorption energies, with some relatively shorter hy- 


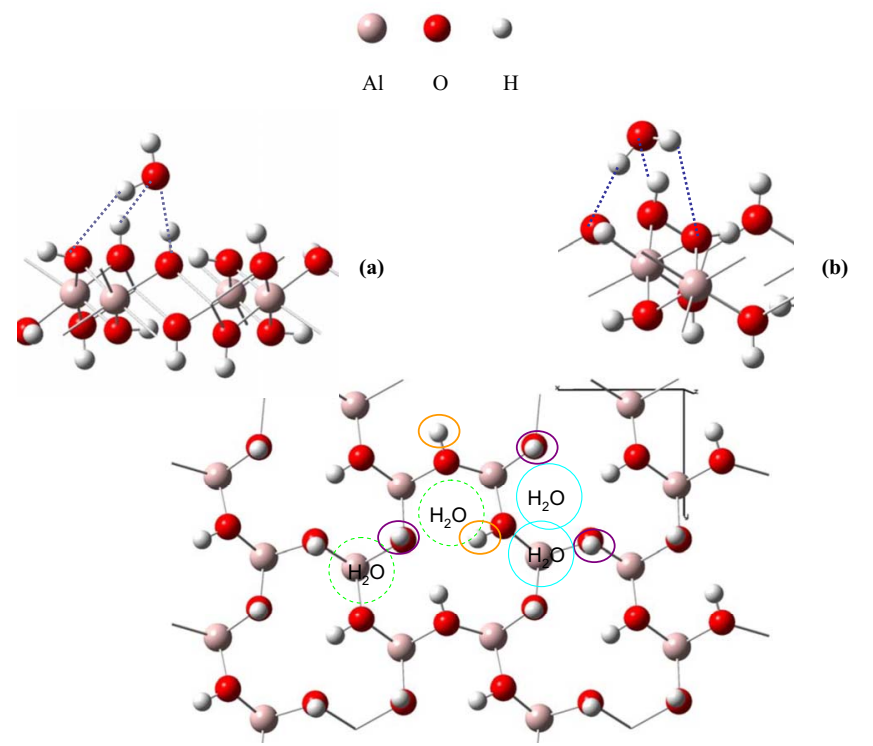

(c)

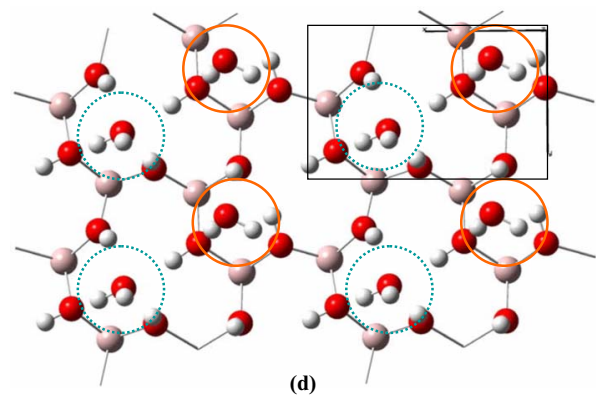

FIG. 5. (Color online) The two possible water adsorption configurations. (a) Water molecule is linked to two surface hydrogen atoms. (b) Water molecule is linked to only one surface hydrogen atom. (c) The four kinds of $\mathrm{H}_{2} \mathrm{O}$ adsorption sites are illustrated: in-plane $\mathrm{H}$ atoms are surrounded in yellow; out-of-plane ones are surrounded in purple. Blue circles: water molecule is linked to two surface hydrogen atoms [see Fig. 5(a)]. Green dash circles: water molecule is linked to only one surface hydrogen atom [see Fig. 5(b)]. Two sites are related to the presence of a sublayer aluminum atom. (d) One of the three possible monolayer coverages of the (001) plane of gibbsite. The black rectangle represents the unit cell. The two water molecules configurations appear within red circle (one out-of-plane $\mathrm{H}$ atom: $0.63 \mathrm{eV}$ ) and blue dot circle (two out-of-plane $\mathrm{H}$ atoms: $0.45 \mathrm{eV}$ ).

drogen bond lengths, whereas the presence of only one outof-plane hydrogen led to weaker water-surface interactions. Finally, two different orientations of water molecules upon the surface were observed. For sites with two out-of-plane hydrogen atoms, the plane of the water molecule was perpendicular to the surface, whereas the molecular plane was parallel to the surface for sites exhibiting two in-plane hydrogen atoms.

Monolayer water coverage of the whole surface is obtained with two water molecules per unit cell, where each water molecule is linked to three surface hydroxyl groups. The value of two molecules per unit cell is in perfect agreement with our experimental thermogravimetric measurements of the isotherm adsorption of water at $30{ }^{\circ} \mathrm{C}$. Since the higher adsorption energies are $0.64 \mathrm{eV}$ (for the three sites exhibiting two out-of-plane hydrogen atoms with no $\mathrm{Al}$ atom in the sublayer), we assumed that three structurally ordered water monolayers could be formed, with very close stabilities. An example of these configurations is represented in
TABLE III. Bond lengths of uranyl cation with five water molecules: Comparison of DFT calculations with experimental EXAFS data obtained in acidic aqueous solution. Distances are in $\AA$ and angles are in degree.

\begin{tabular}{lcc}
\hline \hline & $\mathrm{DFT}^{\mathrm{a}}$ & EXAFS $^{\mathrm{b}}$ \\
\hline$d_{\mathrm{U}=\mathrm{O}}$ & 1.78 & $1.77 \pm 0.02$ \\
$d_{\mathrm{U}-\mathrm{OH}}$ & 2.46 & $2.42 \pm 0.02$ \\
$\Theta(\mathrm{O}=\mathrm{U}=\mathrm{O})$ & 179.7 & 180 \\
\hline \hline
\end{tabular}

${ }^{\mathrm{a}}$ Reference 43.

${ }^{\mathrm{b}}$ Reference 44.

Fig. 5(d). The calculations of these three configurations showed that the adsorption energy of a second water molecule was of about $0.45 \mathrm{eV}$. Therefore, the destabilization due to the adsorption of a second water molecule was weak and ranged from 0.05 to $0.1 \mathrm{eV}$. This is explained by the water interatomic distance (with a minimum of about $4.5 \AA$ ) preventing any $\mathrm{H}$-bonding interactions between water molecules. Therefore, the water layer leads to relatively strong hydrogen bonds with the surface hydroxyl groups, as for the similar octahedral kaolinite surface. ${ }^{40}$ Finally, an alternation of the direction of the dipolar moment of the water molecule is found for the three monolayer configurations: either directed toward the surface or away from it. This phenomenon was previously described by Wang et al., ${ }^{39}$ who demonstrated that water molecules pointing their dipoles toward the surface donated $\mathrm{H}$ bonds to surface $\mathrm{OH}$ groups, whereas water molecules pointing their dipoles away from surface accepted $\mathrm{OH}$ bonds from the surface $\mathrm{OH}$ groups.

\section{Uranyl adsorption}

Since the edge faces are strongly positively charged ${ }^{14,29}$ while in this $p \mathrm{H}$ range the basal charges may be neglected, it was expected that the hydrated uranyl cations are sorbed on the basal faces. Our infrared spectra retrieved this trend. Indeed, the absorption spectra did not show any significant change in the $\mathrm{OH}$ stretching region after the sorption of the uranyl cations in opposition with the anion retention; uranyl cations bonded mainly to the basal faces. According to the literature, a bidentate uranyl complex formation was assumed to be favorable (leading to an inner-sphere complex). ${ }^{43-46}$ Therefore, surface complexes in our computation possessed three water molecules as a first hydration shell (the free uranyl cation in aqueous acidic solution exhibits five hydration shell water molecules). The structure of the uranyl ion from our previous theoretical and experimental studies $^{43,44}$ is presented in Table III.

In the first step, the interaction of the hydrated uranyl cation with the "dry" gibbsite surface was investigated. The basal oxygen atoms of hydroxyl groups with in-plane hydrogen were good candidates to link with the uranium atom since they offer a direct possibility of chelation of the uranium atom in the uranyl's equatorial plane. Three of these kinds of structural sites are available on the (001) surface: two of them hold the same O-O distances (about $2.7 \AA$, sites I and III), whereas the last one exhibits a longer distance (about 3.4 A, site II) (Fig. 6).

Specific distances and differences in energy (relative energy) obtained for the most stable complexes are presented in 


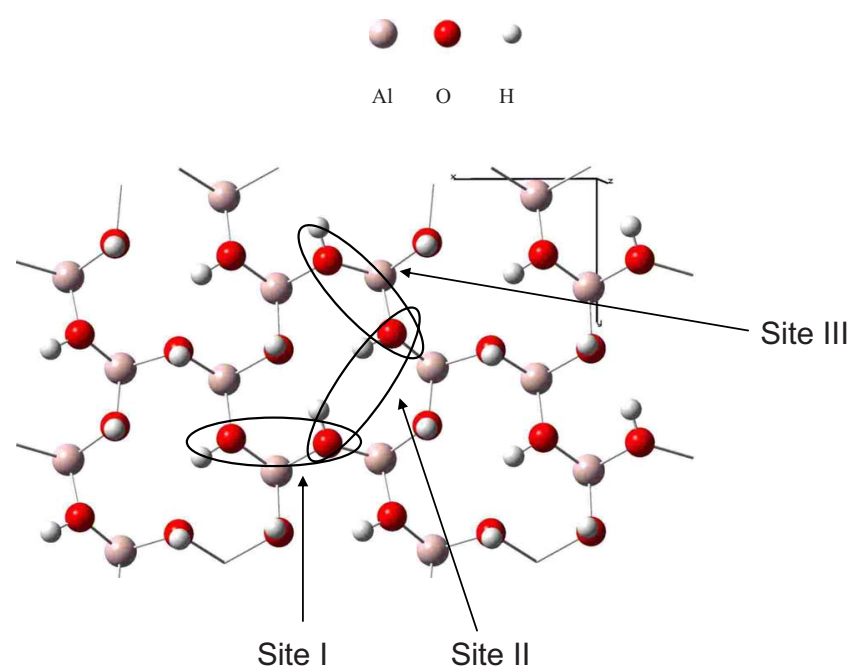

FIG. 6. (Color online) The three possible sites for uranyl adsorption.

Table IV. Figure 7 displays the most stable adsorption configuration among those three sites (site I). All of the created complexes were stabilized throughout a hydrogen-bond network by means of three hydrogen bonds between the surface and the "-yl" oxygen atoms (O-yl) of the uranyl ions whatever the site (I, II, or III) is. One of the O-yl atom possesses two hydrogen interactions, one being weaker than the other (for instance, 1.69 and $2.16 \AA$ for site I). Distances between uranium atom and surface oxygen atoms were in the range of 2.6-2.7 $\AA$. The interaction of uranyl with the gibbsite surface led also to a slight decrease in the $\mathrm{O}=\mathrm{U}=\mathrm{O}$ bond angle (until a minimum of $169^{\circ}$ for site III) and a lengthening of the U-(O-yl) bond [typically about $1.90 \AA$ for all complexes $-1.78 \AA$ for the U-(O-yl) bond of uranyl in the gas phase]. These three initial adsorption sites had similar geometric configurations, consequently leading to strong similarities between the final geometries of the formed complexes.

Nevertheless, oxygen atoms of the (001) plane engaged in these complexes with uranium atoms adopt a fourfold coordination when sorption occurred. A possible local deprotonation of the adsorption hydroxyl groups could thus be assumed, as it was already observed on the oxide surface. ${ }^{45}$ The computation of the $\mathrm{U}-\mathrm{O}_{\text {surface }}$ and also the (O-yl)-H distances (hydrogen bonds) in this case are given in Table IV (deprotonated sites). Geometrical features of this kind of

TABLE IV. Characteristics of the adsorbed complexes (distances and relative energy) with respect to the surface protonation state. Distances are in $\AA$.

\begin{tabular}{|c|c|c|c|}
\hline & $d\left(\mathrm{U}-\mathrm{O}_{\text {surf }}\right)$ & $d(\mathrm{O}-\mathrm{yl} \cdots \mathrm{H})$ & $\begin{array}{c}\Delta E \\
(\mathrm{eV})\end{array}$ \\
\hline \multicolumn{4}{|c|}{ Protonated } \\
\hline Site I & $2.61-2.67$ & $1.56-1.69-2.16$ & 0 \\
\hline Site II & $2.58-2.66$ & $1.68-1.74-2.12$ & 0.23 \\
\hline Site III & $2.56-2.71$ & $1.75-1.78-2.31$ & 0.48 \\
\hline \multicolumn{4}{|c|}{ Deprotonated sites } \\
\hline Site I & $2.15-2.19$ & $1.61-1.77-2.08$ & 0 \\
\hline Site II & $2.12-2.18$ & $1.68-1.81-1.97$ & 0.46 \\
\hline Site III & $2.13-2.21$ & $1.85-1.85-2.45$ & 0.30 \\
\hline
\end{tabular}

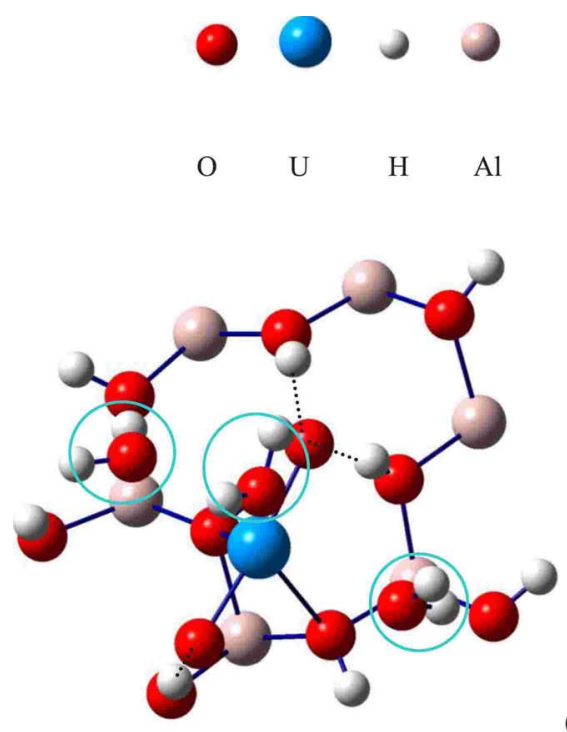

(a)

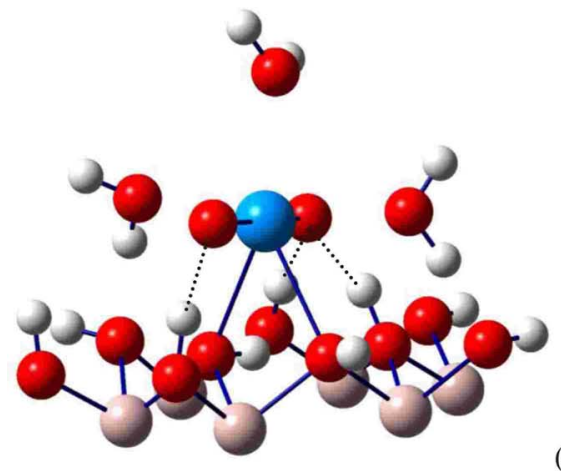

(b)

FIG. 7. (Color online) The most stable calculated complex. Hydrogen bonds are in black dash lines; water molecules are in circles. (a) Top view and (b) side view.

configuration are the following. First, the $\mathrm{O}-\mathrm{U}-\mathrm{O}$ bond angle was highly distorted $\left(153^{\circ}, 141^{\circ}\right.$, and $158^{\circ}$ for sites I, II, and III, respectively), as was already observed within periodic DFT calculations of uranyl adsorption on hydroxylated alumina ${ }^{47}$ and $\mathrm{TiO}_{2}{ }^{45}$ This behavior could be coherent with the low bending frequency of the uranyl moiety $\left(208 \mathrm{~cm}^{-1}\right) .{ }^{48}$ Second, the averaged $\mathrm{U}=\mathrm{O}$ distances were very similar to the ones observed for protonated complexes, but a stronger interaction took place between uranyl and the surface. The $\mathrm{U}-\mathrm{O}_{\text {surface }}$ distances were shortened by about $0.5 \AA$ compared with the protonated complexes, whereas distances between the three remaining water molecules and the uranium atom increased to about $0.1 \AA$.

In the second step, the first water monolayer has been included in the uranyl adsorption process in order to take into account part of the solvent effect. Even though the main features of the adsorbed complexes remained unchanged, $\mathrm{U}-(\mathrm{O}-\mathrm{yl})$ bond lengths slightly increased, hydrogen bonds being created between the $\mathrm{O}$-yl atom and the water monolayer. $\mathrm{U}-\mathrm{O}_{\text {surface }}$ distances remained unchanged except for the most stable site (site I) whose distances increased to 2.53 and $2.87 \AA$. This could be explained by the formation, in this case, of three stronger hydrogen bonds $(1.70,1.75$, and $1.79 \AA$ ), which led to a translation of the molecule upon the 


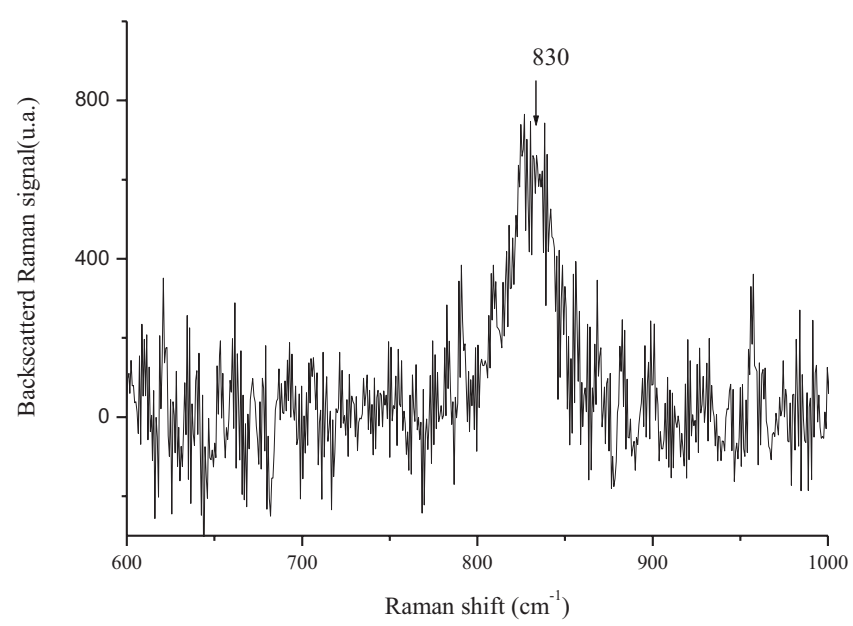

FIG. 8. Difference Raman spectrum of adsorbed uranyl cations at a $p H$ value of 4 . The difference corresponds to the subtraction of the Raman spectrum obtained after adsorption by the initial sample spectrum.

surface. Lengthening of U-(O-yl) distances was also observed when deprotonation is considered. In a general way, global characteristics of the adsorbed complexes were not altered (U-O distances were still between 2.1 and $2.2 \AA$ ).

To summarize calculation results, even if several configurations had to be considered on the surface, all of them converged to a similar structure of adsorbed uranyl complex on the (001) plane. Local deprotonation of oxygen atoms involved in bonds was also considered, leading to a significant decrease in the $\mathrm{U}-\mathrm{O}_{\text {surface }}$ bonds revealing a covalent bond character. Only one complex configuration was determined on this gibbsite face. At last, the presence of a water monolayer did not induce any major changes in the adsorption geometry in both cases (protonated sites or not) but enhanced hydrogen bonding between the adsorbed molecule and the surface.

These results were validated by experimental Raman and TRLFS data. The Raman spectrum displayed a weak inelastic signal with adsorption that was characteristic of the symmetric stretching mode of uranyl cations. ${ }^{49,50}$ The difference spectrum obtained by a normalized subtraction of the initial sample Raman spectrum by the sorbed sample Raman spectrum is displayed in Fig. 8. The inelastic signal of sorbed uranyl groups was centered at $830 \mathrm{~cm}^{-1}$ with a low full width at half maximum of about $30 \mathrm{~cm}^{-1}$ and a symmetric shape. These characteristics were a priori inconsistent with a signal due to several structurally different surface complexes. Moreover, characteristic wavenumbers of different possible aqueous complexes in this $p \mathrm{H}$ range ${ }^{49}$ would tend to show that here, the collected Raman signal of the stretching modes of uranyl did not correspond to uranyl in aqueous solution characterized by the highest wavenumber in this $p \mathrm{H}$ range. ${ }^{49}$ The wavenumbers were not low enough to correspond to any precipitated aggregates or sorbed polymers of uranyl cations. ${ }^{51}$ Consequently, the sorbed uranyl species was strongly perturbed by adsorption, with an equatorial plane not composed of four or five water molecules but rather three water molecules and two surface oxygen groups (bidentate complex). ${ }^{49,52}$ The presence of the asymmetric stretching and the bending modes in the Raman spectrum, which could con-

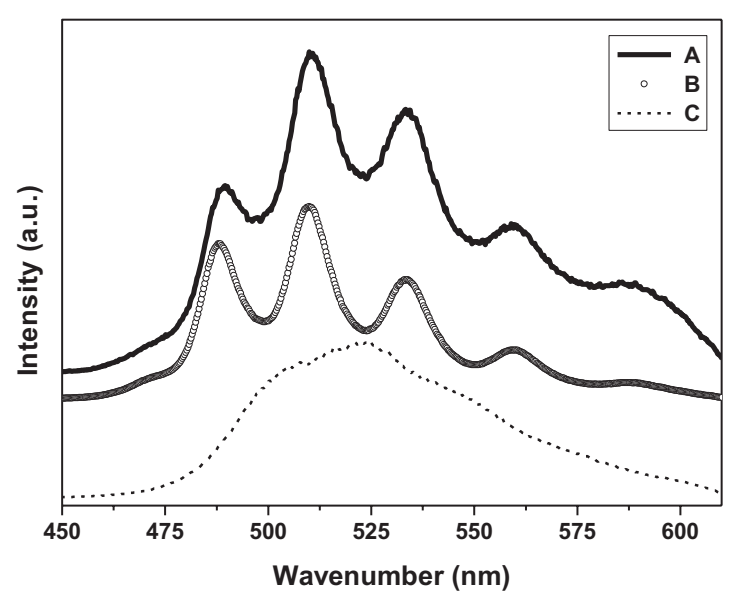

FIG. 9. Fluorescence spectra of uranyl sorbed onto gibbsite for two delays after the laser pulse [(a) $0.2 \mu$ s and (c) $20 \mu \mathrm{s}]$ and (b) in aqueous solution.

firm the computed bended structure of the sorbed uranyl, were not observed here because of a too weak Raman signal. The infrared signals of these modes were overlapped by the strong absorptions of the gibbsite modes and were not usable either.

Our interpretation of the Raman data were in agreement with the TRFLS measurements performed considering in situ samples (powder in contact with the solution) in order to avoid any changes in the system during the drying step. Whatever the considered uranium concentration $\left(10^{-4} M\right.$ or $\left.10^{-3} M\right)$ and the ionic strength $(0.1 M$ or $1 M)$ are, the fluorescence spectra exhibited the same feature (Fig. 9): for a delay equal to $0.2 \mu$ s after the laser pulse, four peaks were clearly observed, located at 489, 510, 533, and $559 \mathrm{~nm}$. The analysis of the fluorescence decay profiles led to two different lifetimes: 1.8 and $15 \mu \mathrm{s}$. In order to confirm the presence of several species, the fluorescence spectrum was recorded $20 \mu$ s after the laser pulse to obtain only the spectrum of the species presenting the longer lifetime $(15 \mu \mathrm{s})$. No difference has been observed whatever the U(VI) concentration and the ionic strength are. The general shape of the obtained spectrum was a broad emission band centered at $523 \mathrm{~nm}$ (Fig. 9). The shorter decay time $(1.8 \mu \mathrm{s})$ was similar to the lifetimes generally reported for the aqueous $\mathrm{UO}_{2}{ }^{2+}$ ion. ${ }^{53}$ Since the experiments were performed with the solid in suspension, part of the total amount of cation initially introduced could still be in solution (sorption percentage lower than 100\%), 4,6 and, consequently, the fluorescence spectrum recorded with $0.2 \mu$ s as delay time should be the convolution of the fluorescence spectra of aqueous and sorbed uranyl ions. To test this assumption, the emission spectra of uranyl in solution ( $p \mathrm{H}=3$, before contact with the powder) were recorded. It presented the common classical vibronic structure of aqueous $\mathrm{UO}_{2}{ }^{2+}$ with six peaks located at 474, 488, 510, 534, 560, and $588 \mathrm{~nm}$, and the associated decay time was measured as $1.7 \mu \mathrm{s}$. This value identical to the shorter one obtained for the suspensions led us to conclude that only the species presenting the longer lifetime $(15 \mu \mathrm{s})$ corresponded to uranyl surface species. The general shape of the fluorescence spectra for $0.2 \mu$ s after the laser pulse can thus be considered as the convolution of the emission spectra of both free aqueous 
uranyl ion and uranium-surface species (spectrum obtained $20 \mu$ s after the laser pulse). These Raman and TRLFS results showed that only one type of uranium adsorption site was present on the (001) gibbsite face at $p \mathrm{H}=3$ as well as for $[\mathrm{U}(\mathrm{VI})]=10^{-4}$ and $10^{-3} \mathrm{M}$, in perfect agreement with DFT calculations, which demonstrated the existence of only one site upon the surface. Moreover, as the spectroscopic parameters of the sorbed species were the same at $0.1 M$ and $1 M$ ionic strengths, the formation of inner-sphere complexes was suggested. Indeed, at a high ionic strength the retention via the formation of outer-sphere complexes was strongly unfavored, while the formation of inner-sphere complexes was not influenced at all. ${ }^{54}$

\section{CONCLUSION}

This study combined experimental and theoretical approaches to investigate the uranyl cation interaction with gibbsite in order to get more insight into the possible retention processes of this mineral into soils. First, we focused on the bulk gibbsite structure. Periodic DFT simulations are in good agreement with the $\mathrm{O}-\mathrm{H}$ bond lengths and geometrical configurations, which were experimentally determined. Calculations supplied the mean values for respectively in-plane and out-of-plane hydrogen atoms of 0.981 and $0.991 \AA$ (the difference being $\Delta d=0.010 \AA$ ), in good agreement with IR measurements displaying mean values of 0.955 and $0.967 \AA$ (the difference being $\Delta d=0.012 \AA$ ).

On the basis of experimental results, IR measurements, and previously published surface charge behaviors, only the uranyl interaction with the (001) face of gibbsite was considered. In order to study the interaction of water molecules and uranyl cations with this face, the surface was modeled with an optimized two-layer model. Weak interactions existing between the gibbsite layers allow us to use a two-layer model.

The first water monolayer without uranyl cations was made of a mix of two water adsorption structures: the water dipolar direction was directed either toward the surface or away from it. This feature has already been observed by means of molecular dynamic simulations. For both adsorption structures, a relatively strong hydrogen-bond network was created with the surface hydroxyl groups (formation of water cluster was not observed).

The interaction of the aqueous uranyl cation with the surface was then investigated. The potential adsorption sites were defined as oxygen atoms belonging to hydroxyl groups possessing in-plane hydrogen atoms because of a direct accessibility for the $U$ atom with the surface. The interaction of uranyl with all the three different $\mathrm{O}-\mathrm{O}$ sites finally led to a bidentate adsorption mode due to the high symmetrical configuration of the (001) face. Hydrogen bonding was found to take place with respect to the -yl oxygen atom and seemed to stabilize the adsorption configuration. If a local deprotonation of the hydroxyl groups was considered during the adsorption process, a more covalent bonding of uranium with the surface was observed $\left[\Delta d\left(\mathrm{U}-\mathrm{O}_{\text {surface }}\right)=-0.4 \AA\right.$ relative to the protonated site]. The addition of a water monolayer did not significantly modify the structure of the surface complexes.

Finally, DFT calculations put forward the existence of only one type of adsorption site upon the surface, even if various complex stabilities were detected. This has been confirmed by means of Raman and TRLFS measurements, which clearly demonstrated the formation of a unique surface complex.

Temperature and solvent effects will be taken into account in a following study by means of the Car-Parinello molecular dynamics in order to fully describe the structure and the behavior of the uranyl cations at the solid-liquid interface.

\section{ACKNOWLEDGMENTS}

This work was supported by Agence Nationale de la recherché Grant No. ANR-05-BLAN-0245-03. A generous allotment of CPU time on GRIF (http://www.grif.fr) is gratefully acknowledged.

${ }^{1}$ R. Drot, J. Roques, and E. Simoni, C. R. Chim. 10, 1078 (2007).

${ }^{2}$ A. R. Gupta and B. Venkataramani, Bull. Chem. Soc. Jpn. 61, 1357 (1988).

${ }^{3}$ H.-S. Chang, G. V. Korshin, Z. Wang, and J. M. Zachara, Environ. Sci. Technol. 40, 1244 (2006).

${ }^{4}$ N. Baumann, V. Brendler, T. Arnold, G. Geipel, and G. Bernhard, J. Colloid Interface Sci. 290, 318 (2005).

${ }^{5}$ A. Froideval, C. Gaillard, R. Barillon, I. Rossini, and J. L. Hazemann, Geochim. Cosmochim. Acta 70, 5270 (2006).

${ }^{6}$ Z. Hongxia, X. Yongxin, and T. Zuyi, Colloids Surf., A 252, 1 (2005).

${ }^{7}$ B. Humbert, J. Grausem, and D. Courjon, J. Phys. Chem. B 108, 15714 (2004); J. Grausem, B. Humbert, M. Spajer, D. Courjon, A. Burneau, and J. Oswalt, J. Raman Spectrosc. 30, 833 (1999).

${ }^{8}$ J. Frenzel, A. F. Oliveira, H. A. Duarte, T. Heine, and G. Seifert, Z. Anorg. Allg. Chem. 631, 1267 (2005); S. D. Fleming, A. L. Rohl, M.-Y. Lee, J. D. Gale, and G. Parkinson, J. Cryst. Growth 209, 159 (2000); S. D. Fleming, A. L. Rohl, S. C. Parker, and G. M. Parkinson, J. Phys. Chem. B 105, 5099 (2001).

${ }^{9}$ J. D. Gale, A. L. Rohl, V. Milman, and M. C. Warren, J. Phys. Chem. B 105, 10236 (2001).

${ }^{10}$ M. Digne, P. Sautet, P. Raybaud, H. Toulhoat, and A. Emilio, J. Phys. Chem. B 106, 5155 (2002).

${ }^{11}$ E. Balan, M. Lazzeri, G. Morin, and F. Mauri, Am. Mineral. 91, 115 (2006).

${ }^{12}$ H. Saalfeld and M. Weede, Z. Kristallogr. 139, 129 (1974).

${ }^{13}$ J. Ganor, J. Mogollon, and A. Lasaga, Geochim. Cosmochim. Acta 63, 1635 (1999).

${ }^{14}$ T. Hiemstra and W. H. V. Riemsdijk, J. Colloid Interface Sci. 301, 1 (2006).

${ }^{15}$ T. Hiemstra, P. Venema, and W. H. V. Riemsdijk, J. Colloid Interface Sci. 184, 680 (1996); T. Hiemstra, H. Yong, and W. H. V. Riemsdijk, Langmuir 15, 5942 (1999); T. Hiemstra, J. C. M. D. Wit, and W. H. V. Riemsdijk, J. Colloid Interface Sci. 133, 105 (1989); T. Hiemstra, W. H. V. Riemsdijk, and G. H. Bolt, ibid. 133, 91 (1989).

${ }^{16}$ M. C. Jodin, F. Gaboriaud, and B. Humbert, J. Colloid Interface Sci. 287, 581 (2005).

${ }^{17}$ G. Kresse and J. Hafner, Phys. Rev. B 47, 558 (1993).

${ }^{18}$ J. P. Perdew and Y. Wang, Phys. Rev. B 45, 13244 (1992).

${ }^{19}$ G. Kresse and D. Joubert, Phys. Rev. B 59, 1758 (1999).

${ }^{20}$ H. J. Monkhorst and J. D. Pack, Phys. Rev. B 13, 5188 (1976)

${ }^{21}$ M. Methfessel and A. Paxton, Phys. Rev. B 40, 3616 (1989).

${ }^{22}$ M.-C. Jodin, F. Gaboriaud, and B. Humbert, Am. Mineral. 89, 1456 (2004).

${ }^{23}$ N. Phambu, B. Humbert, and A. Burneau, Langmuir 16, 6200 (2000).

${ }^{24}$ E. Rinnert, Ph.D. thesis, Université Henri Poincaré, 2001.

${ }^{25}$ I. Grenthe, J. Fuger, R. J. M. Konongs, R. J. Lemire, A. B. Muller, C. Nguyen-Trung, and H. Wanner, Chemical Thermodynamics of Uranium, 
edited by H. Wanner and I. Forest (OECD Nuclear Agency, Data Bank, Issy-les-Moulineaux, France, 1992).

${ }^{26}$ R. F. Giese Jnr, Acta Crystallogr., Sect. B: Struct. Crystallogr. Cryst. Chem. 32, 1719 (1976).

${ }^{27}$ J. M. R. Mercury, P. Pena, A. H. de Aza, D. Sheptyakov, and X. Turrillas, J. Am. Ceram. Soc. 89, 3728 (2006).

${ }^{28}$ S. L. Wang and C. T. Johnson, Am. Mineral. 85, 739 (2000).

${ }^{29}$ M. C. Jodin, Ph.D. thesis, Université Henri Poincaré, 2004.

${ }^{30}$ H. D. Lutz, J. Mol. Struct. 646, 227 (2003).

${ }^{31}$ H. D. Lutz and C. Jung, J. Mol. Struct. 404, 63 (1997).

${ }^{32}$ R. Mortel and H. D. Lutz, J. Mol. Struct. 648, 171 (2003).

${ }^{33}$ G. Herzberg, Molecular Spectra and Molecular Structure (Van Nordstrand, New York, 1950).

${ }^{34}$ K. Nakamoto, Kagaku no Ryoiki, Zokan 23, 79 (1956); A. Burneau, J. Mol. Liq. 46, 99 (1990); J. D. Kubicki and S. E. Apitz, Am. Mineral. 83, 1054 (1998); E. Libowitzky and G. R. Rossman, ibid. 82, 1111 (1997); V. Szalay, L. Kovacs, M. Wohlecke, and E. Libowitzky, Chem. Phys. Lett. 354, 56 (2002).

${ }^{35}$ J. M. R. Mercury, P. Pena, A. H. de Aza, D. Sheptayakov, and X. Turrillas, J. Am. Ceram. Soc. 89, 3728 (2006).

${ }^{36}$ See EPAPS Document No. E-JCPSA6-129-018848 for calculations on out-of-plane and in-plane $\mathrm{O}-\mathrm{H}$ bond lengths for the bulk geometry generated average values. For more information on EPAPS, see http:// www.aip.org/pubservs/epaps.html.

${ }^{37}$ E. Molis, O. Barrès, H. Marchand, E. Sauzéat, B. Humbert, and F. Thomas, Colloids Surf., A 163, 283 (2000).

${ }^{38}$ B. J. Teppen, K. Rasmussen, P. M. Bertsch, D. M. Miller, and L. Schafer, J. Phys. Chem. B 101, 1579 (1997).

${ }^{39}$ J. Wang, A. G. Kalinichev, and R. J. Kirkpatrick, Geochim. Cosmochim. Acta 70, 562 (2006).

${ }^{40}$ D. Tunega, M. H. Gerzabek, and H. Lischka, J. Phys. Chem. B 108, 5930
(2004)

${ }^{41}$ D. Tunega, G. Haberhauer, M. H. Gerzabek, and H. Lischka, Langmuir 18, 139 (2002)

${ }^{42}$ D. Tunega, L. Benco, G. Haberhauer, M. H. Gerzaber, and H. Lischka, J. Phys. Chem. B 106, 11515 (2002).

${ }^{43}$ H. Perron, C. Domain, J. Roques, R. Drot, E. Simoni, and H. Catalette, Radiochim. Acta 94, 601 (2006)

${ }^{44}$ C. Den Auwer, R. Drot, E. Simoni, S. D. Conradson, M. Gailhanou, and J. Mustre de Leon, New J. Chem. 27, 648 (2003).

${ }^{45}$ H. Perron, C. Domain, J. Roques, R. Drot, E. Simoni, and H. Catalette, Inorg. Chem. 45, 6568 (2006).

${ }^{46}$ H. Perron, Ph.D. thesis, Paris-Sud 11 University, 2007.

${ }^{47}$ L. V. Moskaleva, V. A. Nasluzov, and N. Rösch, Langmuir 22, 2141 (2006).

${ }^{48}$ M. García-Hernández, C. Lauterbach, S. Krüger, A. Matveev, and N. Rösch, J. Comput. Chem. 23, 834 (2002).

${ }^{49}$ F. Quilès and A. Burneau, Vib. Spectrosc. 23, 231 (2000).

${ }^{50}$ H. Aubriet, B. Humbert, and M. Perdicakis, Radiochim. Acta 94, 657 (2006).

${ }^{51}$ M. L. Palacios and S. H. Taylor, Appl. Spectrosc. 54, 1372 (2000); M. Amme, B. Renker, B. Schid, M. P. Feth, B. H. Bertagnolli, and W. Dobelin, J. Nucl. Mater. 306, 202 (2002).

${ }^{52}$ U. Wahlgren, H. Moll, I. Grenthe, B. Schimmelpfenning, L. Maron, V. Vallet, and O. Gropen, J. Phys. Chem. A 103, 8257 (1999).

${ }^{53}$ C. Moulin and P. Decambox, Anal. Chem. 67, 348 (1995).

${ }^{54}$ A. Kowal-Fouchard, R. Drot, E. Simoni, N. Marmier, F. Fromage, and J.-J. Ehrardt, New J. Chem. 28, 864 (2004); D. Xu, Q. L. Ning, X. Zhou, C. L. Chen, A. D. Wu, and X. K. Wang, J. Radioanal. Nucl. Chem. 266, 419 (2005); A. J. Fairhurst, P. Warwick, and S. Richardson, Colloids Surf., A 99, 187 (1995); W. M. Dong, X. K. Wang, X. Y. Bian, A. X. Wang, J. Z. Du, and Z. Y. Tao, Appl. Radiat. Isot. 54, 603 (2001). 